\title{
Impact of asymmetric uncertainties in ice sheet dynamics on regional sea level projections
}

\author{
Renske C. de Winter ${ }^{1}$, Thomas J. Reerink ${ }^{2}$, Aimée B. A. Slangen ${ }^{3}$, Hylke de Vries ${ }^{4}$, Tamsin Edwards ${ }^{5}$, and \\ Roderik S. W. van de Wal ${ }^{2}$ \\ ${ }^{1}$ Institute for Marine and Atmospheric research Utrecht, Physical Geography, Utrecht University, \\ Heidelberglaan 2, 3584 CS Utrecht, the Netherlands \\ ${ }^{2}$ Institute for Marine and Atmospheric research Utrecht, Utrecht University, Princetonplein 5, \\ 3584 CC Utrecht, the Netherlands \\ ${ }^{3}$ NIOZ Royal Institute for Sea Research, Department of Estuarine and Delta Systems, \\ and Utrecht University, Korringaweg 7, 4401 NT Yerseke, the Netherlands \\ ${ }^{4}$ Royal Netherlands Meteorological Institute (KNMI), P.O. Box 201, 3730 AE De Bilt, the Netherlands \\ ${ }^{5}$ Open University, Milton Keynes, UK
}

Correspondence to: Renske C.de Winter (r.c.dewinter@uu.nl)

Received: 28 February 2017 - Discussion started: 3 April 2017

Revised: 8 September 2017 - Accepted: 15 September 2017 - Published: 4 December 2017

\begin{abstract}
Currently a paradigm shift is made from global averaged to spatially variable sea level change (SLC) projections. Traditionally, the contribution from ice sheet mass loss to SLC is considered to be symmetrically distributed. However, several assessments suggest that the probability distribution of dynamical ice sheet mass loss is asymmetrically distributed towards higher SLC values. Here we show how asymmetric probability distributions of dynamical ice sheet mass loss impact the high-end uncertainties of regional SLC projections across the globe. For this purpose we use distributions of dynamical ice sheet mass loss presented by Church et al. (2013), De Vries and Van de Wal (2015) and Ritz et al. (2015). The global average median can be $0.18 \mathrm{~m}$ higher compared to symmetric distributions based on IPCCAR5, but the change in the global average 95th percentile SLC is considerably larger with a shift of $0.32 \mathrm{~m}$. Locally the 90th, 95th and 97.5th SLC percentiles exceed $+1.4,+1.6$ and $+1.8 \mathrm{~m}$. The high-end percentiles of SLC projections are highly sensitive to the precise shape of the probability distributions of dynamical ice sheet mass loss. The shift towards higher values is of importance for coastal safety strategies as they are based on the high-end percentiles of projections.
\end{abstract}

\section{Introduction}

Sea level change (SLC) will be one of the major impacts of climate change in the 21st century (Nicholls et al., 2011; Cazenave and Le Cozannet, 2014). Coastal safety standards are often formulated by analyzing the high percentiles of the probability distribution, resulting in magnitudes of events with an acceptable return frequency (Katsman et al., 2011). These types of studies are executed in order to analyze events that are infrequent but expected to have a large impact on economy and society (Jonkman et al., 2011). Including highend SLC projections is therefore the logical next step in coastal safety analysis, since coastal decision-making also needs information on the upper boundary of possible future sea level when assessing future extreme events (De Winter and Ruessink, 2017). This requires two aspects: the transformation from global average SLC projections to regional SLC projections and the provision of insight of the uncertainties of these regional SLC.

Local impact studies (e.g., De Winter and Ruessink, 2017) show that the amount of SLC may affect coasts and the corresponding mitigation measures significantly. This emphasizes the need for regional SLC projections, since the amount of SLC can deviate from global average values due to changes in ocean currents, thermal expansion and gravitational and rotational effects induced by land ice and terrestrial ground 
and surface water mass changes (Mitrovica et al., 2001). Recent studies show those spatially variable SLC projections (Slangen et al., 2012; Perrette et al., 2013; Slangen et al., 2014; Lyu et al., 2014; Kopp et al., 2014; Grinsted et al., 2015).

There are several components that contribute to SLC: surface mass balance changes of glaciers and ice sheets, global steric plus dynamic topography and atmospheric pressure, groundwater depletion, glacial isostatic adjustment (GIA) and dynamical ice sheet mass loss. Particularly the uncertainty of the last component, dynamical ice sheet mass loss, is under debate (Vieli and Payne, 2005; Pattyn et al., 2012; DeConto and Pollard, 2016). Traditionally, the contribution from dynamical ice sheet mass loss to SLC is assessed by analyzing the median and the standard deviation. Two independent expert-judgment-based studies (Bamber and Aspinall, 2013; Horton et al., 2014) and a model-based assessment (Ritz et al., 2015) concluded that the probability distributions of the ice dynamical contribution may be asymmetrical. The method in the expert-judgment-based studies is criticized (Gregory et al., 2014; Clark et al., 2015; De Vries and Van de Wal, 2015), but from a physical point of view it cannot be excluded that the ice dynamical contribution of ice sheets has a larger uncertainty towards higher-SLC values (Jacobs et al., 2011; Ritz et al., 2015; Pollard et al., 2015) than considered so far. This is due to nonlinear behavior of the ice dynamics and ice shelve collapse and the possibility of a threshold affecting the rate of decay of the ice sheetshelf system. At the same time there is a large difference between the expert-informed dynamical ice sheet mass loss and most of the numerical modeling studies (Little et al., 2013; Golledge et al., 2015; Ritz et al., 2015). Particular, DeConto and Pollard (2016) project high values due to ice cliff instability in combination with parameterizations for rapid ice shelf disintegration. These higher projections are primarily caused by the possible collapse of marine-based sectors of the Antarctic ice sheet (AIS) (Church et al., 2013; Favier et al., 2014). An asymmetric probability distribution for the Greenland ice sheet (GIS) can also not be excluded due to a rapid decay of marine-terminating glaciers (Nick et al., 2013). This implies that there is a greater uncertainty for events with an uncertainty above 1 standard deviation in the future contribution of dynamical ice mass changes to SLC than previously assumed, which will influence the projections of higher percentiles of the SLC probability distribution (Bamber and Aspinall, 2013; Horton et al., 2014). As such, it is necessary to examine the consequences of asymmetric probability distributions for the ice dynamical contribution on regional sea level projections.

Higher percentiles of the probability distribution are used to study uncertainties of SLC projections, in line with coastal safety assessments that use a return-frequency-based approaches to determine safety levels (Nicholls et al., 2011; Hinkel et al., 2015). Previous studies of the high-end percentiles of SLC projections for specific locations like the
Netherlands (De Vries et al., 2014) or northern Europe (Grinsted et al., 2015) and at network of tide-gauge sites (Kopp et al., 2014) show that adopting asymmetric distributions for ice sheet mass loss have large impacts on high percentiles of SLC projections. Kopp et al. (2014) use a data assimilation technique for tide-gauge sites combining historical data of sea levels with IPCC-AR5 SLC projections and expert judgement analysis of Bamber and Aspinall (2013) to estimate the impact of the ice dynamical contribution. They use the study of Bamber and Aspinall (2013) to calibrate the shape of tail of the distribution and concluded that at most location uncertainties of future SLC projections are driven by uncertainties in the ice sheet contribution. In contrast to Kopp et al. (2014), Grinsted et al. (2015) use a distribution presented by Bamber and Aspinall (2013) to project regional SLC pattern of northern Europe and the uncertainty ranges therein. They concluded that with the distribution from Bamber and Aspinall (2013), the 95th percentile may be an additional $0.9 \mathrm{~m}$ above median. Both studies assume the contribution of the AIS to be independent of scenario.

The main objective of this paper is to analyze the sensitivity of higher percentile of regional SLC projections to asymmetric probability distributions for dynamical ice sheet mass loss. This is done by comparing the impacts of the probability distributions of Church et al. (2013), De Vries and Van de Wal (2015) and Ritz et al. (2015) on high-end regional SLC projections. Especially the development of the tail of the probability distribution is of interest because these higher percentiles are, in contrast to the mean or median, often used to determine safety standards.

\section{Methods}

\subsection{Components contributing to sea level rise}

In order to make a comparison between symmetric and asymmetric contributions of dynamical ice sheet mass loss to SLC all other components contributing to SLC are kept the same for all simulations. Regional SLC fields of Slangen et al. (2014) (their Fig. 1) under RCP8.5 (Representative Concentration Pathway) climate scenario (Moss et al., 2010) are used for all contributions except dynamic ice sheet mass loss. The regional SLC fields of Slangen et al. (2014) include contributions to SLC from surface mass balance of glaciers and ice sheets under RCP8.5 (their Figs. 1b and 2b), global steric plus dynamic topography and atmospheric pressure loading under RCP8.5 (their Figs. 1d and 2d), scenario-independent groundwater depletion (their Figs. 1f and 2f) and scenarioindependent GIA (their Figs. $1 \mathrm{~g}$ and $2 \mathrm{~g}$ ).

The normal, symmetric contributions for dynamical ice sheet mass loss are based on the median and likely range from IPCC-AR5 (Church et al., 2013, their Table 13.5) (green, dash-dotted line Fig. 1a-b and e-f). Over the last few years, several new probability density functions (PDFs) 
(a) Ice dynamical contribution GIS

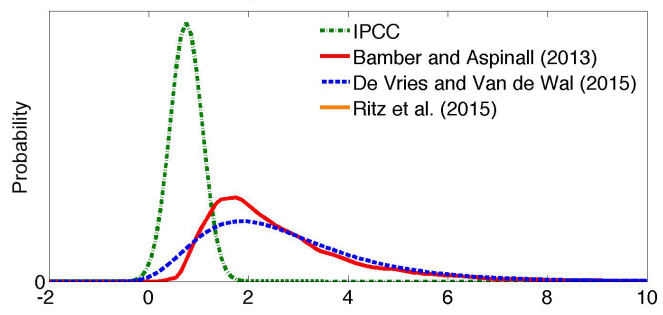

(b) Ice dynamical contribution AIS

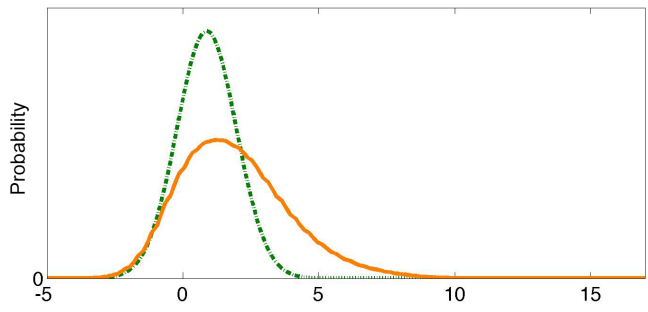

(c) Ice dynamical contribution WAIS

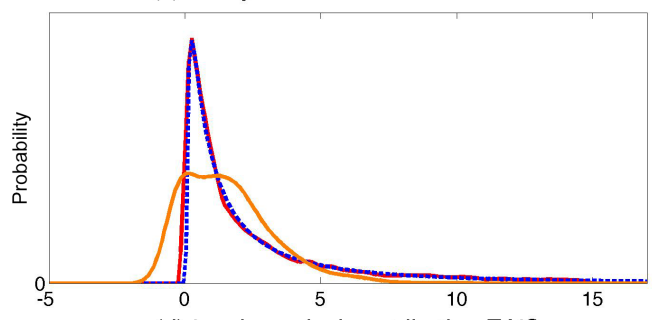

(d) Ice dynamical contribution EAIS

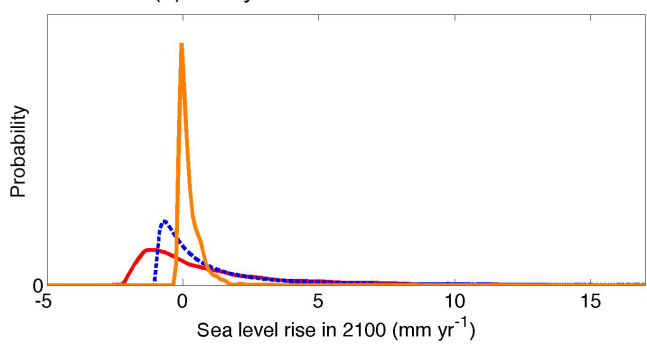

(e) Ice dynamical contribution GIS

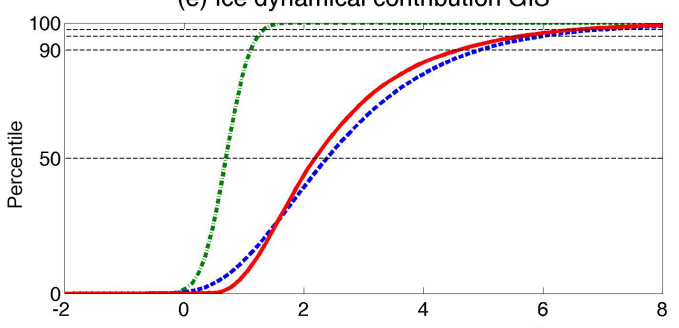

(f) Ice dynamical contribution AIS

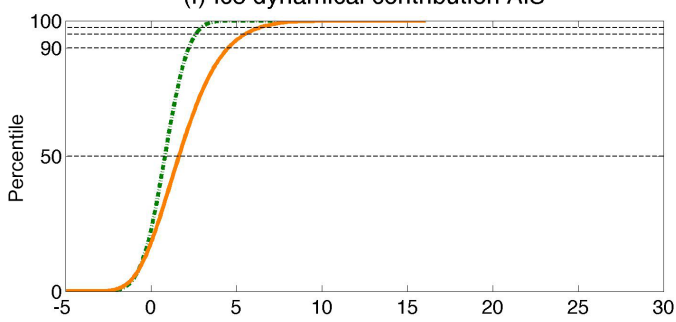

(g) Ice dynamical contribution WAIS

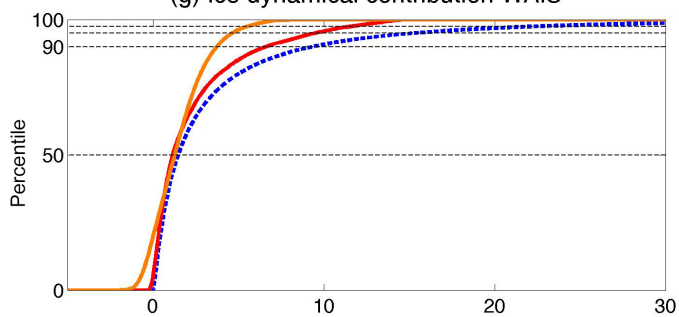

(h) Ice dynamical contribution EAIS

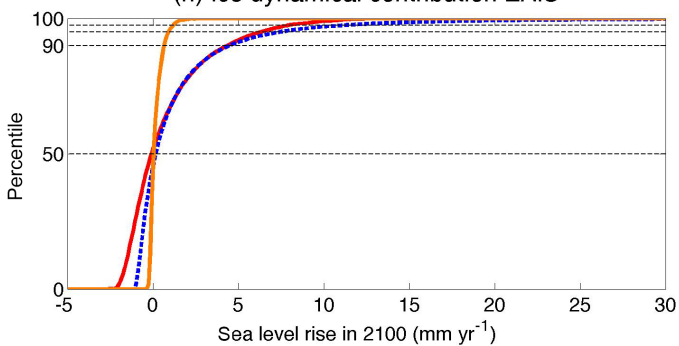

Figure 1. Probability density functions (left column) and cumulative density functions (CDFs) (right column) for dynamical ice sheet mass loss of Greenland ice sheet (GIS), Antarctic ice sheet (AIS), West Antarctic ice sheet (WAIS) and East Antarctic ice sheet (EAIS). IPCC-AR5 does not have separate distributions for WAIS and EAIS. In the CDFs the dotted lines indicate the 90th, 95th and 97.5th percentiles.

of the contribution of dynamical ice sheet mass loss to SLC have been published (Bamber and Aspinall, 2013; De Vries and Van de Wal, 2015; Ritz et al., 2015). These new studies differ in median (indicated by the 50th percentile in the right column of Fig. 1) and asymmetry (shape of the PDF). The PDFs show the skewness/asymmetry of a distribution, whereas changes in higher percentiles (the right tail of the PDF) are visible in the cumulative density function (CDF) of Fig. 1. The PDFs of De Vries and Van de Wal (2015) (hereafter VW15) are chosen to study impacts of an asymmetric contribution of ice sheet mass loss on higher percentiles of SLC projections because this data set contains distributions of all ice sheets (West Antarctica ice sheet or WAIS, East Antarctica ice sheet or EAIS, and Greenland ice sheet or GIS). VW15 reanalyzed the data from Bamber and As- pinall (2013) (hereafter BA13). As the expert judgments in BA13 were not weighted equally, VW15 more rigorously estimated the lack of consensus in the projection by fitting a log-normal distribution to the data and deriving uncertainties for the different levels of confidence. The effect of different input distributions on high-end SLC percentiles is analyzed by comparing the SLC projection composed with a dynamical ice sheet contribution of WAIS, EAIS and GIS according to VW15 and with the SLC projections containing probability distributions of Ritz et al. (2015) for WAIS and EAIS and the GIS contribution of IPCC-AR5. An overview on how the data are used and combined is depicted in Fig. 2.

Mass loss of an ice sheet does not result in a globally uniform rise in sea level as a result of the gravitational effect, the added water mass will be redistributed according to a 


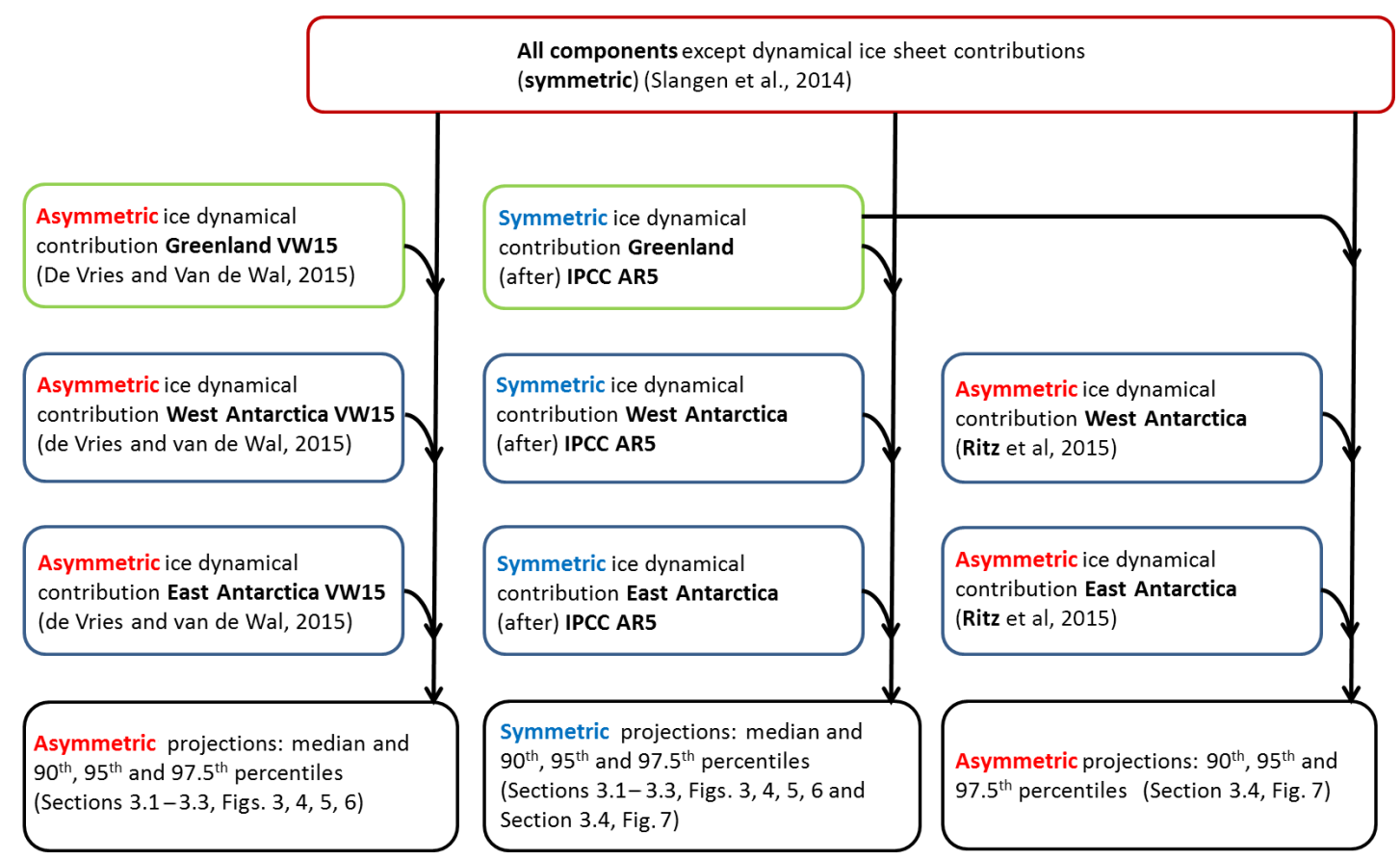

Figure 2. Overview of the used data: which data are combined and in which section the computations are discussed. Each box represents a distribution for the global average; these global average data are converted to a regional contribution using the fingerprints of Slangen et al. (2014).

geographical pattern, the so-called fingerprint. Fingerprints of each ice sheet (Slangen et al., 2014) are used to convert the global projections of ice sheet mass loss to regional sea level projections. IPCC-AR5 (Church et al., 2013) does not make a distinction between WAIS and EAIS for the ice dynamical contribution. The contribution to SLC is assumed to originate from WAIS because, relative to the EAIS, this ice sheet is generally considered to make a larger contribution to SLC.

The regional SLC fields of Slangen et al. (2014) and the symmetric IPCC contributions are projections for the period of 1990-2010 to 2080-2100. The asymmetric distributions of VW15 and Ritz et al. (2015) contain SLCs in millimeter per year in 2100. In order to be consistent with the projections of Church et al. (2013) and Slangen et al. (2014), a linear increase in SLC rates between 2010 and 2100 is assumed so that changes between 2010 and 2090 due to dynamical ice sheet mass loss could be analyzed.

Two aspects influence changes in the median between the PDFs constructed with symmetric and asymmetric components. First of all, the medians of the asymmetric projections for ice sheet mass loss are higher compared to the symmetric IPCC distributions (Fig. 1e-h). Secondly, even if the medians of the input PDFs are the same, the final PDF for the SLC projections might be different as a result of the asymmetry yielding higher SLC projections for higher percentiles.

Finally it is important to note that we first assume that all components of SLC are uncorrelated, and eventually a corre- lation between climate-driven projections of SLC and ice dynamical contributions of SLC is also investigated (Sect. 3.3).

\subsection{SEAWISE: combining probability distributions}

Future probability distributions of regional SLC are calculated by combining the probability distributions of the different components that contribute to sea level changes. For this analysis the SEAWISE model is developed. Computations are done on a global grid, with a grid size of $1^{\circ}$ in longitude and latitude.

The composed distribution $P_{\text {com }}(x)$ consists for each $x$ of all contributions of two independent distributions $P_{1}\left(x_{1}\right)$ and $P_{2}\left(x_{2}\right)$ for which the summed $x$-axis values $x_{1}$ and $x_{2}$ add to $x$. Each combination for which $x=x_{1}+x_{2}$ applies yields a contribution of $P_{1}\left(x_{1}\right)$ times $P_{2}\left(x_{2}\right)$ to $P_{\text {com }}(x)$; i.e., summing over all relevant combinations $x=x_{1}+x_{2}$ determines $P_{\text {com }}(x)$ for a certain $x$ :

$P_{\text {com }}(x)=\sum_{m=c}^{d} P_{1}(x-m \Delta x) P_{2}(m \Delta x)$,

where $x$ is the SLC and $P_{1}$ and $P_{2}$ are the probability distributions for SLCs of two individual components. See for example Fig. 3, where the PDF of panels (a) and (b) are combined to calculate the PDF in panel (c). Selecting $99.9 \%$ of the integrated distribution around the mode (the peak of the PDF) defines for each probability distribution a left and right boundary. The distribution is normalized on this selected in- 
terval. The left and right boundaries of $P_{1}$ are defined as $x_{a}$ and $x_{b}$; for $P_{2}$ the left and right boundaries are defined as $x_{c}$ and $x_{d}$. The interval counter, $m$, runs between $c$ and $d$, corresponding with $x_{c}$ and $x_{d}$, while taking $x_{2}=m \Delta x$ and $x_{1}=x-m \Delta x$. To obtain the entire distribution $P_{\text {com }}(x)$, Eq. (1) is calculated from $x_{a}$ up to $x_{b}+x_{d}$.

This combined SLC probability distribution can be combined with a third SLC probability (e.g., Fig. 3d) distribution by a recursive approach and so on until all components that contribute to SLC are combined and $P_{\text {total }}$ is created (e.g., Fig. 3g).

Appendix A1 provides more details on how SEAWISE combines probability distributions if the components are assumed to be correlated.

For the regional projections, $P_{\text {total }}$ is saved for all SLC values as depicted in Fig. 4. For the global projection, per grid point $P_{\text {total }}$ is determined to calculate the specified percentiles (e.g., 90th).

\section{Results}

\subsection{Changes in median}

Combining the SLC probability distribution for the symmetric ice sheet contribution with the probability distribution for all other components to SLC results in an area-averaged global median (50th percentile) SLC of $+0.68 \mathrm{~m}$ in 2090 (Fig. 5a). This is slightly higher than the $+0.63 \mathrm{~m}$ projected in IPCC-AR5 (Church et al., 2013, their Table 13.5). The difference between these projections results from larger projected SLC contributions from glaciers and groundwater depletion in Slangen et al. (2014). Most of the regional SLC projections have a higher median for the simulations where the contribution of ice sheet mass loss to SLC is considered to be asymmetric according to VW15. Using the asymmetric VW15 data rather than the symmetrical IPCC-based distributions for the ice dynamical components results in an areaaveraged global median of $+0.86 \mathrm{~m}$ (Fig. 5b). This shift in median of $0.18 \mathrm{~m}$ (Fig. $5 \mathrm{c}$ ) indicates that the estimate we use for the contribution of ice sheet mass loss is directed to higher values when using the asymmetric components. The explanation for this is twofold. First of all, medians of the contribution following the ice dynamical mass loss of IPCC-AR5 are 0.70 and $0.82 \mathrm{~mm} \mathrm{yr}^{-1}$ for GIS and AIS, respectively. In contrast to median contributions of $2.39 \mathrm{~mm} \mathrm{yr}^{-1}$ for GIS, they are $1.49 \mathrm{~mm} \mathrm{yr}^{-1}$ for EAIS and $0.17 \mathrm{~mm} \mathrm{yr}^{-1}$ for WAIS for the VW15 distributions (Fig. 1e-h). Second, even if the medians are assumed to be the same, the asymmetry towards higher SLC values results in a small shift of the median in the combined projection.

More important than the average shift in median is that both regional SLC projections (with symmetric and asymmetric components) show large regional variability. These spatial variations (Fig. 5a-b) are the result of changes in
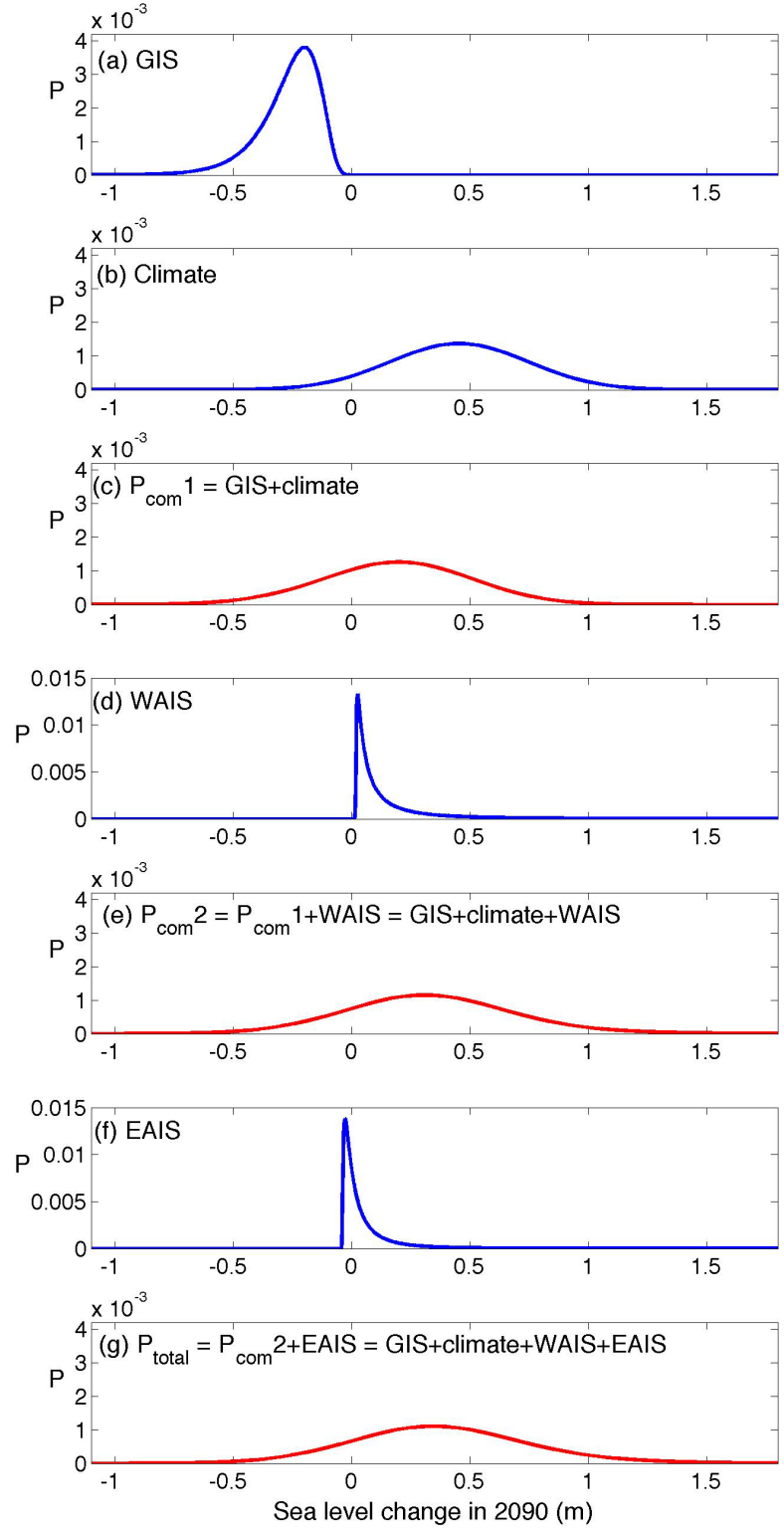

Figure 3. Example of the merging of several probability density functions (PDFs), here depicted for Denmark Strait (Fig. 4a). The input PDFs of dynamical ice sheet mass loss of the Greenland ice sheet (GIS) and climate forcing are merged following Eq. (1) to calculate $P_{\text {com }} 1$. This combined PDF is subsequently combined with a PDF of the ice dynamical contribution of the West Antarctic ice sheet (WAIS) to sea level change to $P_{\text {com }} 2$; finally the ice dynamical contribution of the East Antarctic ice sheet (EAIS) is added to construct $P_{\text {total }}$. The input PDFs (blue lines panels a, b, d and f) vary regional, as depicted in Fig. A1 for three locations.

global steric plus dynamic topography and atmospheric pressure loading, surface mass balance of glaciers and ice sheets, groundwater depletion, GIA (Slangen et al., 2014) and the impact of the ice dynamical contribution. The latter is because mass redistribution from the land to the ocean does not result in a globally uniform increase in sea level 

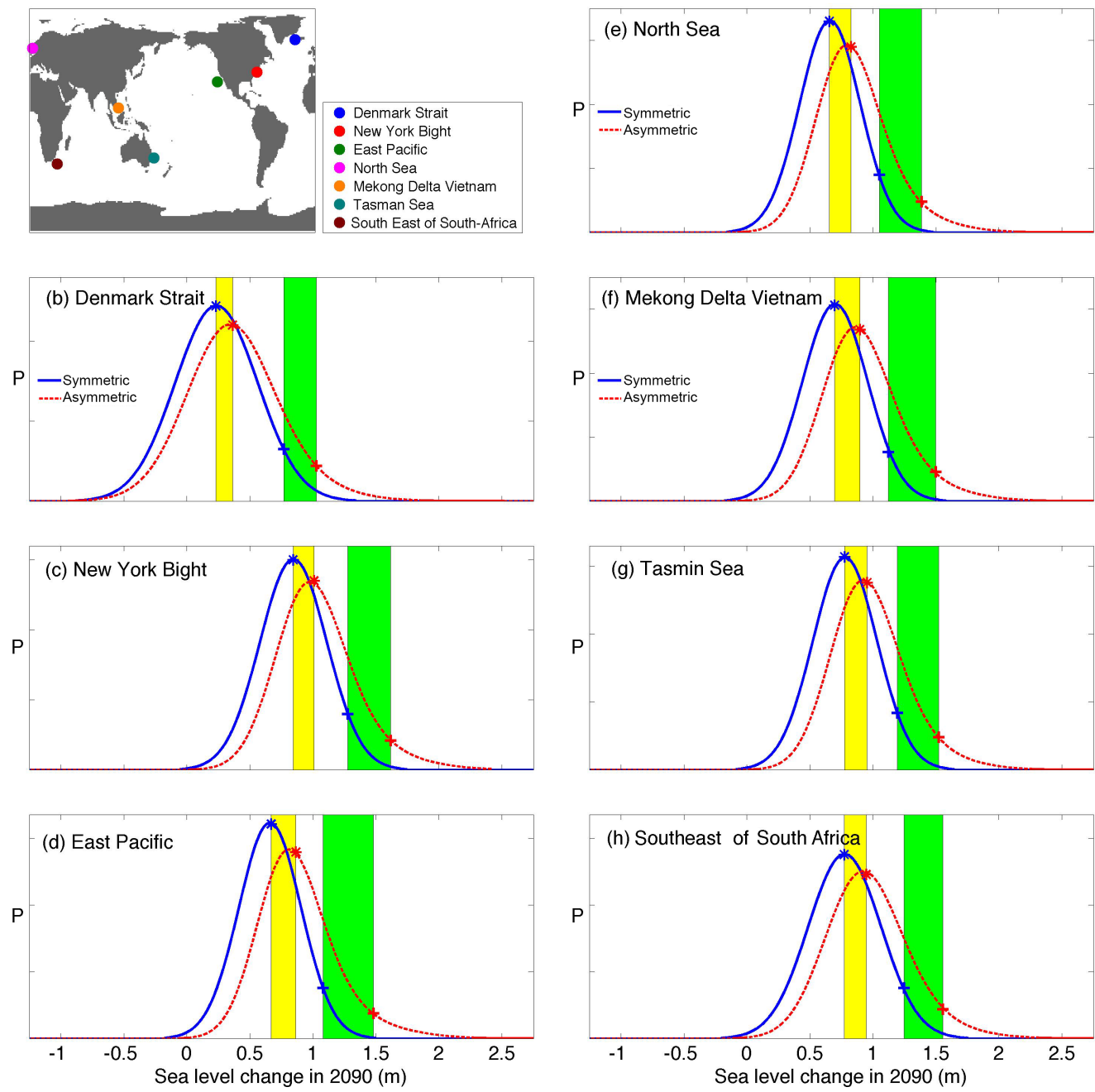

Figure 4. Total combined probability density of sea level change by 2090, for three locations marked in panel (a): (b) Denmark Strait, (c) New York Bight, (d) east Pacific, (e) North Sea, (f) Mekong Delta Vietnam, (g) Tasmin Sea (east of Australia) and (h) southeast of South Africa. Regional projections by Slangen et al. (2014) following RCP8.5 combined with (blue, solid lines) the symmetrical IPCC-based distributions of ice sheet mass loss and (red, dotted lines) asymmetrical VW15-distribution of ice sheet mass loss. The stars indicate the median and the plus sign indicate the 95th percentile. The difference in median is indicated in yellow and the difference in the 95th percentile in green. Note that the increase of the 95th percentile is larger than the increase in median. The input distributions for each location are depicted in Fig. A1.

(Slangen et al., 2012, 2014; Perrette et al., 2013; Lyu et al., 2014). Near an ice sheet, for instance, mass loss of this ice sheet will result in a sea level fall, since the gravitational pull of the ice sheet becomes less when the mass decreases. In the far field of an ice sheet the rise of sea level will be above average. Using symmetric IPCC-based dynamical ice sheet mass loss contribution to SLC, the median SLC varies regionally from -1.07 to $+1.03 \mathrm{~m}$ (Fig. 5a). Assuming the VW15 asymmetric dynamical ice sheet mass loss, the median SLC projection ranges regionally from $-1.90 \mathrm{~m}$ close to the location of mass loss to $+1.03 \mathrm{~m}$ in the far field (Fig. 5b), with the largest differences in the central Pacific and Arctic oceans.

\subsection{Changes in higher percentiles}

Changes in the tails of the probability distribution are much larger than the shift in median, as indicated by the probability distribution for seven locations (Fig. 4). At the Denmark Strait (northwest of Iceland), the GIS contribution to SLC is negative and the gravitational pull of GIS becomes less when mass is lost; subsequently less water is attracted towards GIS and sea levels are projected to fall compared to present day at this location. In contrast, the EAIS and WAIS have a strong positive contribution at this location (Fig. 3), as the Denmark Strait is in the far field of EAIS and WAIS. As a result the GIS contribution has a long tail towards negative values (Figs. 3a and $\mathrm{A} 1 \mathrm{~b}-\mathrm{c})$, whereas EAIS and WAIS contribute positively to SLC (Fig. A1d-e). Consequently, the total probability dis- 
(a)

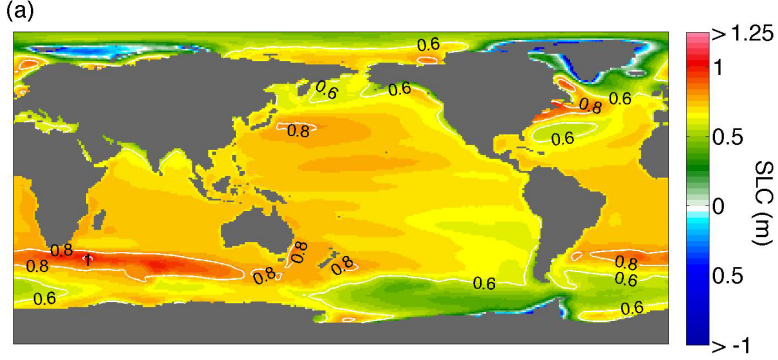

(b)

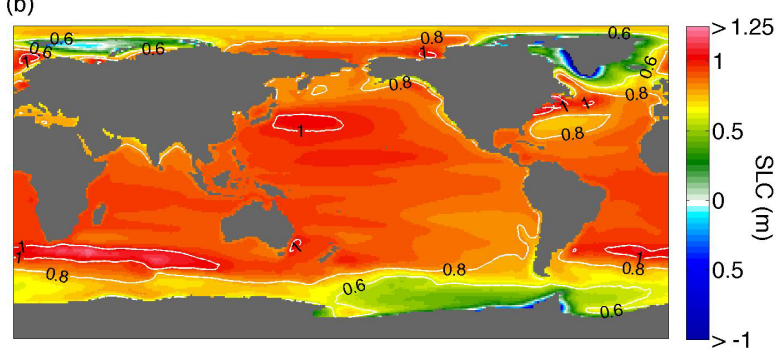

(c)

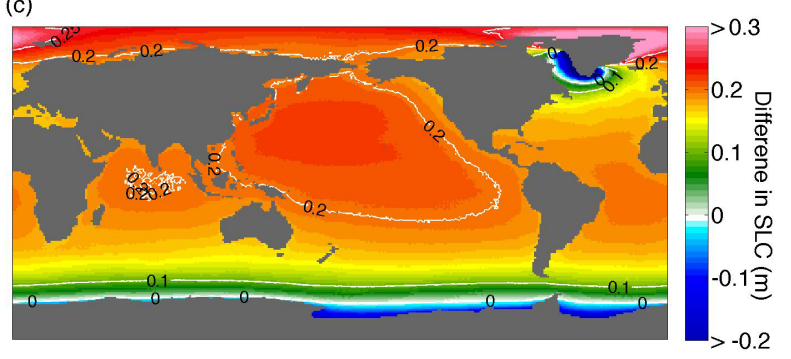

Figure 5. Median sea level rise projections by 2090; regional projections of Slangen et al. (2014) following climate scenario RCP8.5 combined with the contributions to sea level rise due to dynamical ice sheet mass loss: (a) symmetrically distributed ((Church et al., 2013)) and (b) asymmetrically VW15 distributed (De Vries and Van de Wal, 2015). (c) The difference in median $(\mathbf{b}-\mathbf{a})$. The areaaveraged global median depicted in panel (a) is 0.68 and $0.86 \mathrm{~m}$ in panel (b). The area-averaged global median difference between panels (b) and (a) is $0.18 \mathrm{~m}$.

tribution including the asymmetric VW15 contribution of dynamical ice sheet mass loss to SLC is broader compared to the probability densities that include IPCC-AR5 values for dynamic ice sheet mass loss (Fig. 4b).

At locations where the GIS contribution is near zero (e.g., New York Bight, Fig. 4c), the shape of the tail in the combined distribution of the asymmetric simulations is dominated by the AIS contribution (Fig. A1e). The largest changes occur where the contributions of the GIS, EAIS and WAIS are all positive (Fig. A1). At these locations, for example the east Pacific Ocean, the Mekong Delta, Pacific Ocean east of Australia and the Indian Ocean near South Africa, the tail of the probability distribution becomes skewed towards higher SLC values (Fig. 4d, f-h).
The spatial pattern of the (change in) the higher percentiles including the asymmetric VW15 dynamical ice sheet contribution are shown in Fig. 6. The 90th, 95th and 97.5th percentiles of SLC locally exceed $+1.4,+1.6$ and $+1.8 \mathrm{~m}$ in large parts of the ocean (Fig. 6a-c). Asymmetric VW15 distributions of ice sheet mass loss alter the global average 90th, 95th and 97.5th percentiles by $+0.27,+0.32$ and $+0.39 \mathrm{~m}$, respectively, compared to the symmetric IPCC-AR5 probability distributions (Fig. 6d-f). This is considerably larger than the shift in the median, which has a global average of $+0.18 \mathrm{~m}$. It also shows that the difference increases for larger percentiles. The asymmetric VW15 distribution results in a shift of the upper percentiles to lower values near GIS and WAIS. This is the result of a decrease in the gravitational attraction due to the mass loss of the neighboring ice sheet and hence a negative contribution to SLC. The change in higher percentiles is, however, positive in other places, with a maximum where the fingerprints of the different ice sheet are all larger than one. For the asymmetric VW15 projections the increase between the 90th and 95th percentile is of the same magnitude as the increase between the 95th and 97.5th percentile.

As mentioned before, the globally average value increases by $+0.18 \mathrm{~m}$ if the ice dynamical contribution is asymmetric compared to symmetric (Fig. 5c). However, this difference is much smaller than the difference in the higher percentiles, with a shift of the globally average 97.5 th percentile of $+0.39 \mathrm{~m}$. In order to determine whether the increase in sea level of higher percentiles is related to generally higher values (higher median) or to the shape of the distribution, we corrected the change of the higher percentiles for the change in local median SLC for each location (see Fig. 7 where Fig. $5 \mathrm{c}$ is subtracted from Fig. 6a-c). Generally, the corrected higher percentiles of SLC are still much larger compared to the projections with symmetric IPCC-based ice dynamical contributions, with changes up to $0.3 \mathrm{~m}$ (Fig. $7 \mathrm{~d}-\mathrm{f}$ ). For both analyses (corrected and uncorrected for changes in the median), the increase to higher SLC values becomes more pronounced for higher percentiles. This has significant implications for the high-end uncertainties of future SLC projections, since with a higher mean sea level the allowance for extreme events becomes lower as critical thresholds are exceeded more frequently (Slangen et al., 2017).

\subsection{Correlation between ice sheet mass losses and steric SLC}

Based on the IPCC-AR5 (Church et al., 2013) we initially assume the dynamical ice sheet contribution to SLC to be independent of climate-change-induced changes in SLC. Recent studies (Bamber and Aspinall, 2013), however, suggest a dependency between climatological changes and dynamical ice sheet mass loss as the processes driving the changes are partly similar, implying that the contribution of GIS and WAIS to SLC are correlated. This correlated dependency 
(a)

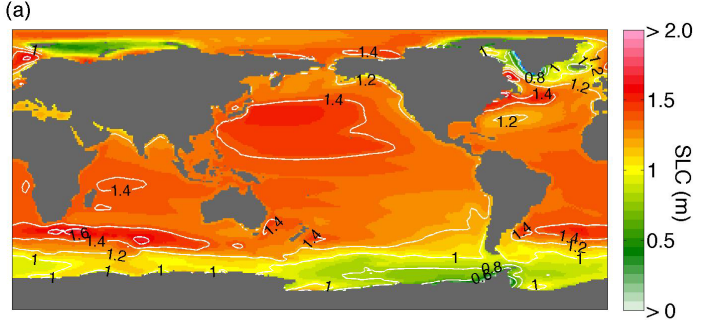

(b)

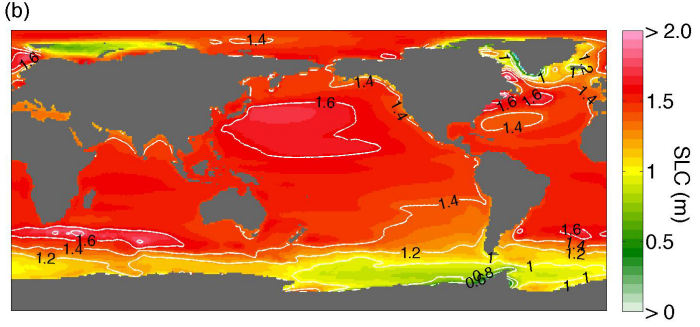

(c)

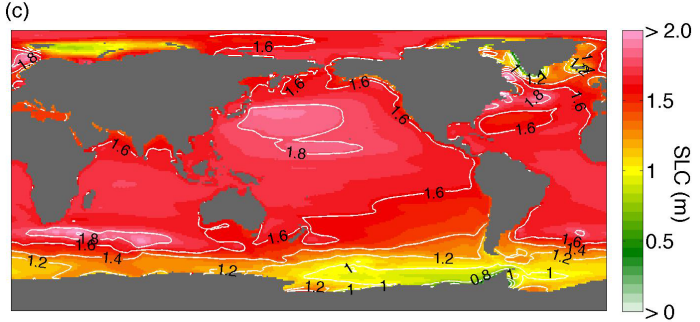

(d)

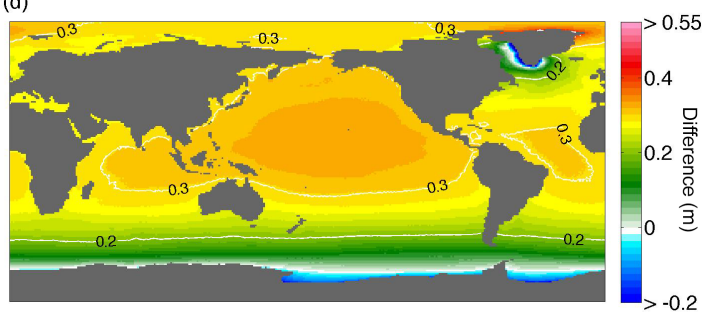

(e)

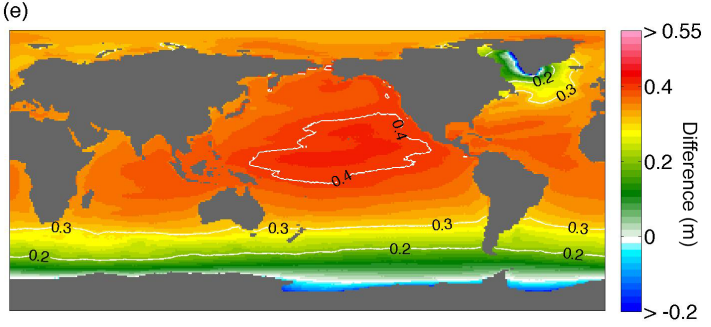

(f)

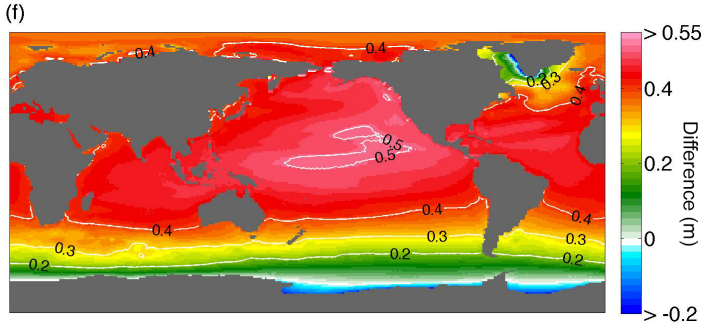

Figure 6. Sea level change (SLC) projections for high-end percentiles and the change therein by 2090. Left column: (a) 90th, (b) 95th and (c) 97.5th percentile for the asymmetric VW15 distribution of dynamical ice sheet mass loss combined with regional SLC projections following RCP8.5 (Slangen et al., 2014). Right column: difference between (d) 90th, (e) 95th and (f) 97.5th percentile for asymmetric VW15 and symmetric IPCC-based contribution, both combined with regional SLC projections following RCP8.5 (Slangen et al., 2014). Percentiles for the symmetric IPCC-based probability distribution are depicted in Fig. A2.

is investigated by examining changes in the 90th, 95th and 97.5th percentiles when dynamical ice sheet mass loss of GIS is fully correlated with climate-driven changes in SLC. Dynamical ice sheet mass loss of WAIS to SLC is subsequently assumed to be correlated with $70 \%$ this combined probability distribution (Appendix A1). Mass loss of EAIS is still considered to be independent of the other components. A result of the correlation is that the combined distribution is less wide, with low- and high-end percentiles that are closer to the mean. For the asymmetric distribution, the high-end percentiles of SLC will therefore be lower compared to simulations where the SLC components are merged independently (Fig. A3). A correlation between the different components that contribute to SLC would therefore result in a smaller range of sea levels. A better physical understanding of whether, and to what extent, dynamical changes are coupled to climate changes is therefore important.

\subsection{Impact of different input distributions}

To analyze the impact of different PDFs of dynamical ice mass loss on regional SLC, we computed the 90th, 95th and 97th percentiles for projections that include probability distributions for EAIS and WAIS following Ritz et al. (2015). The GIS contributions are based on IPCC-AR5, while the probability distributions are combined with the regional fields of Slangen et al. (2014). In these simulations SLC projections increase nonlinearly for the analyzed percentile; e.g the increase is approximately the same between 90th-95th and 95th-97.5th (Fig. 8a-c). A difference of the regional Ritz projections compared to the regional IPCC projections is that mainly in the Northern Hemisphere the SLC values shift towards higher values, up to $0.2 \mathrm{~m}$ (Fig. $8 \mathrm{~d}-\mathrm{f}$ ). This is related to the fingerprints of EAIS and WAIS by mass loss in the far field of the ice sheet. The range of projected SLC is different in the regional Ritz projections compared to the regional VW15 projections (Fig. A4). This is not only because the contribution of GIS is based on IPCC-AR5 but also because the input distributions of EAIS and WAIS have a less heavy tail towards high SLC values (Fig. 1e-h). This analysis shows the importance of accurate probability distributions for dynamical ice sheet mass loss for higher percentiles of regional SLC, which based on ice dynamical models. 
(a)

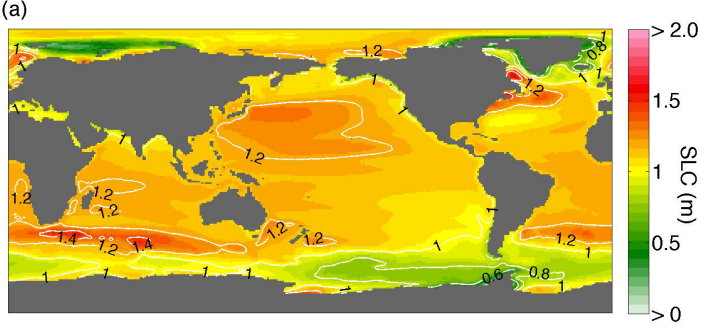

(b)

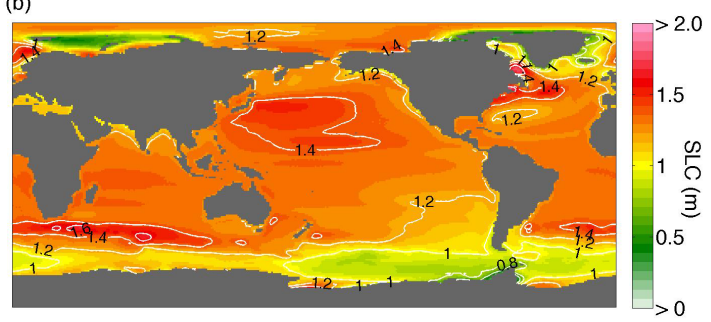

(c)

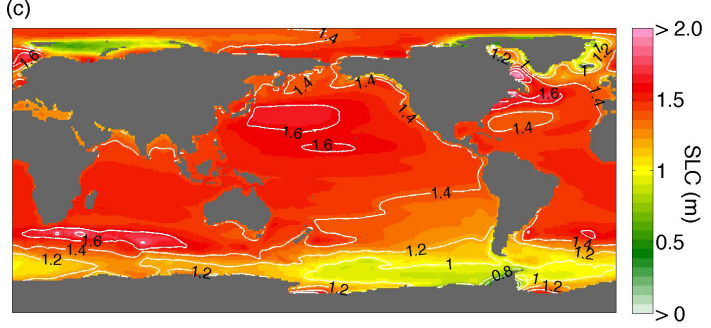

(d)

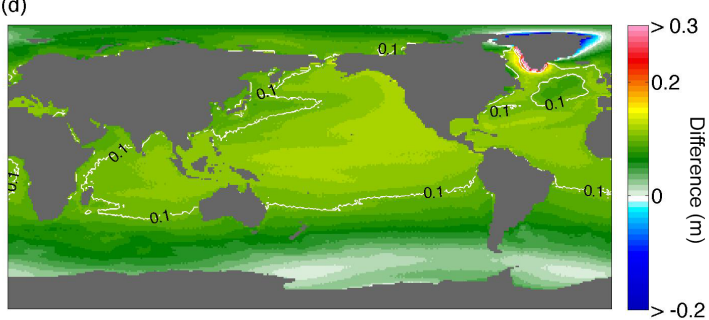

(e)

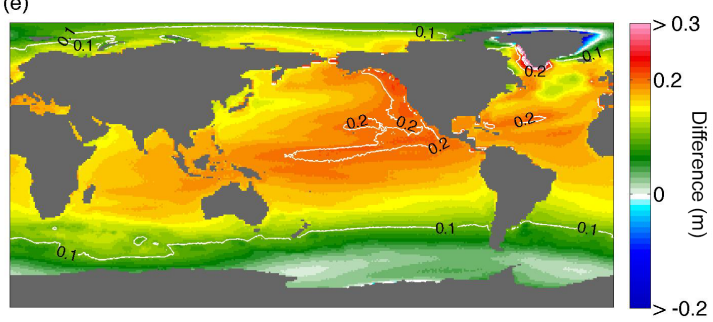

(f)

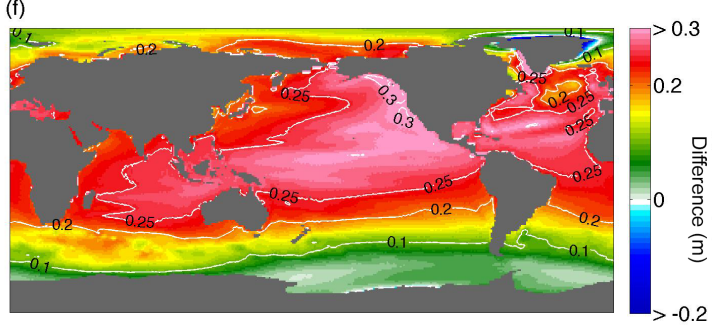

Figure 7. Sea level change (SLC) projections by 2090 for high-end percentiles corrected with shift in local median. Left column: (a) 90 th, (b) 95th and (c) 97.5th percentile for the asymmetric VW15 distribution of ice sheet mass loss combined with regional SLC projections following RCP8.5 (Slangen et al., 2014), corrected with the local shift in median depicted in Fig. 3c. Right column: difference between the asymmetric VW15 (corrected with the difference in local median) and symmetric IPCC-based (both combined with regional SLC projections following RCP8.5; Slangen et al., 2014) for the (d) 90th, (e) 95th and (f) 97.5th percentile.

\section{Discussion}

The asymmetric probability distributions for the contribution of ice sheet mass loss in this research are based on two projections of dynamical ice sheet mass loss. One of these studies (VW15) is based on an expert judgment data set. This approach has a number of limitations. Firstly, the interpretation of the expert data can largely influence the shape of the tail of the probability distribution (De Vries and Van de Wal, 2015). Secondly, according to Gregory et al. (2014) some surveyed experts to the expert analysis by Horton et al. (2014) suggested SLC projections outside a range of physically plausible scenarios. Furthermore, they argue that an expert judgement analysis is an opaque way of data gathering and that especially outliers to high values cannot be verified. The study by Ritz et al. (2015) established a physically based probability distribution of dynamical ice sheet mass loss of the AIS. Indications of the possibility of a collapse of parts of ice sheets (Little et al., 2013) show that the contribution of the AIS to SLC is highly uncertain. For the GIS a physically based probability distribution of dynamical ice sheet mass loss is not available; it is not expected that the probability distribution of the GIS has a large tail towards high SLC values and thus it would be good to replace expert judgement analysis with physically based probability distributions. The data sets for dynamical ice sheet mass loss to SLC available at this moment (Fig. 1 and DeConto and Pollard, 2016) show a large range of values. In this study we show that when these global projections are used for regional SLC projections, the differences in higher percentiles will be amplified for locations in the far field of an ice sheet.

In Sect. 3.3 we analyze the impact of a correlation between climate-induced changes to SLC and ice dynamical contributions to SLC. We show that a correlation between different contributions to SLC impacts the high-end percentiles of the projections to generally slightly lower values. The ratio of correlation is based on an expert judgement analysis (Bamber and Aspinall, 2013). Le Bars et al. (2017) concluded, based on symmetric contributions, that the combined PDFs becomes wider if the contributions are assumed to be correlated, suggesting that the shape of the distribution is also imported. 
(a)

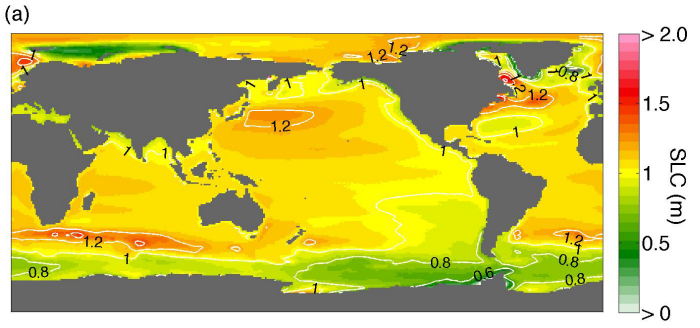

(b)

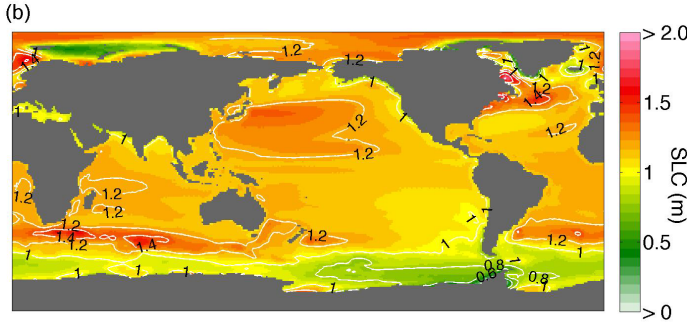

(c)

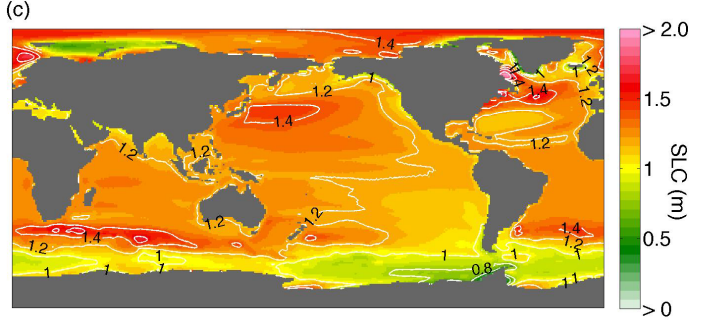

(d)

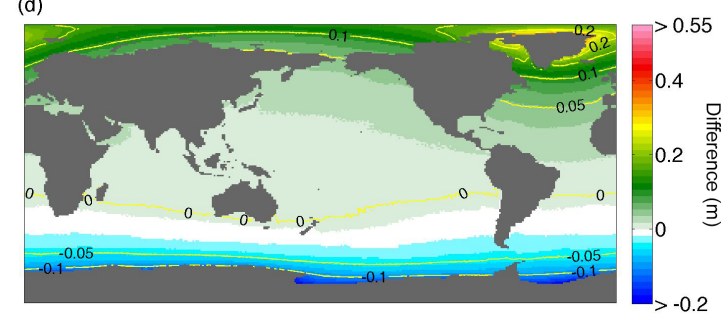

(e)
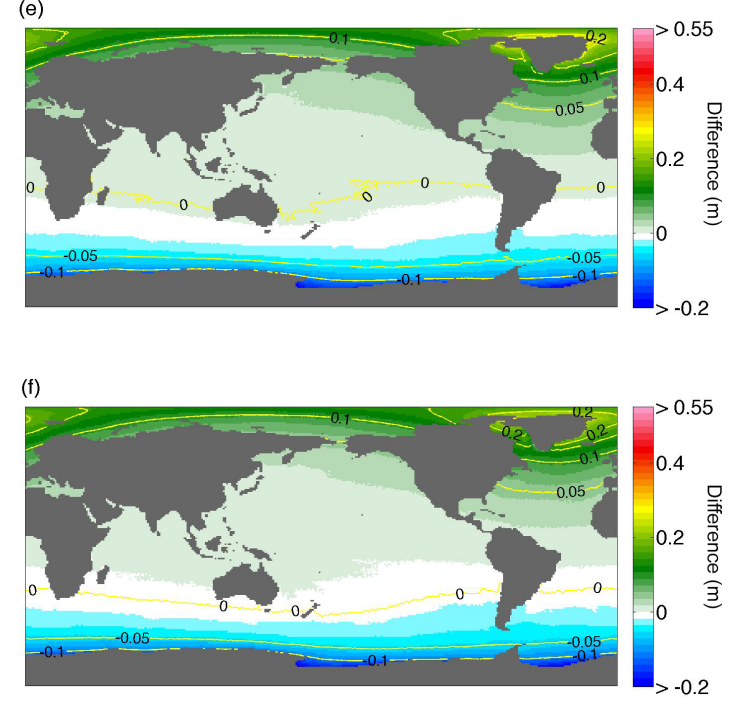

Figure 8. Left column: (a) 90th, (b) 95th and (c) 97.5th percentile for the asymmetric Ritz distribution of dynamical ice sheet mass loss of East and West Antarctica ice sheets (EAIS and WAIS) combined with symmetric IPCC-based contributions of dynamical ice mass loss of the Greenland ice sheet (GIS) and regional sea level change projections following RCP8.5 (Slangen et al., 2014). Right column: difference between (d) 90th, (e) 95th and (f) 97.5th percentile for asymmetric Ritz and symmetric IPCC-based ice dynamical contribution of EAIS and WAIS, both combined with symmetric IPCC-based contributions of dynamical ice mass loss of the Greenland ice sheet (GIS) and regional SLC projections following RCP8.5 (Slangen et al., 2014). Percentiles for the symmetric IPCC-AR5 probability distribution are depicted in Fig. A2.

In coastal safety assessment higher percentiles are often used to calculate return-frequency-based extremes. The uncertainty bands of these extreme events are often used to project whether a specific event is changing significantly under a future climate. The projections of high-end uncertainties also have an uncertainty (De Vries and Van de Wal, 2015, their Figs. 3 and 4). Including this in future studies would make it possible to determine the bandwidth of the tail of the CDF for SLC projections and analyze the significance of extreme SLC.

The method presented here could also be used to analyze the effect of (asymmetrical) uncertainties in other components that contribute to SLC such as thermal expansion (Sriver et al., 2012), changes in ocean currents and temperature (Sallenger Jr. et al., 2012; Yin and Goddard, 2013), or non-climatological local effects (Santamaría-Gómez et al., 2014). Furthermore, in the study of Slangen et al. (2017) SEAWISE is used to determine the impact asymmetric probability distributions on sea level allowances.

\section{Conclusions}

Until recently, SLC studies focused on projections with symmetric uncertainty ranges. Here, we have shown that the tail towards high values of SLC of the probability distribution of dynamical ice sheet mass loss highly influences the 90th, 95th and 97.5th percentiles of regional SLC. This shift of higher percentiles has large regional variability due to local differences in the contribution to SLC from dynamical ice sheet mass loss, related to the distance to the ice sheets of Greenland and East and West Antarctica. Asymmetric distributions of dynamical ice sheet mass loss can affect the median of SLC projections, with a global average shift in median of $0.18 \mathrm{~m}$ for the simulations with the asymmetric distributions of dynamical ice sheet mass loss by De Vries and Van de Wal (2015) compared to the symmetric distributions based on IPCC-AR5. This can be related to a higher input median of the dynamical ice sheet mass loss components and to the skewed tail of the probability distribution towards higher values. The shift of the higher percentiles is 
even more pronounced compared to the shift in median when the contribution of ice sheet dynamics to SLC is assumed to be asymmetrically distributed towards higher values. For the 97.5th percentile the shift can be up to $0.54 \mathrm{~m}$ and over $0.3 \mathrm{~m}$ if the local shift in median is taken into account between the asymmetric distributions by De Vries and Van de Wal (2015) and the symmetric IPCC-based distributions.

The 90th, 95th and 97.5th percentiles of regional SLC are strongly effected by the analyzed asymmetric probability distribution. The difference between the asymmetric input probability distributions of dynamical ice mass loss of De Vries and Van de Wal (2015) and Ritz et al. (2015) shows that the high-end percentiles can differ up to $0.5 \mathrm{~m}$ depending on the applied PDF for dynamical ice sheet mass loss. Hence, we conclude that the uncertainty in ice sheet dynamics dominates the uncertainty in the local high-end percentiles of SLC projections. This is highly relevant for flooding safety since with a higher mean sea level critical thresholds are exceeded more frequently under extreme events, such as storm surges. Focusing on the median regional SLC with a symmetric uncertainty range underestimates future climate-change-related flooding risks.

Data availability. The data set is freely available at https: //dataverse.nl/dataset.xhtml?persistentId=hdl:10411/X8BTEB (De Winter and Reerink, 2017). 


\section{Appendix A}

\section{A1 SEAWISE: combining correlated PDFs}

In order to analyze the effect of dependent components that contribute to SLC, Eq. (1) has to be generalized for combining correlated components. Therefore a correlation function is constructed that uses fractional intervals instead of $x$ values. For each distribution the interval between the left and the right boundary is scaled from 0 to 1 . The fractional interval $f_{1}$ for $P_{1}$ is defined by

$f_{1}=\frac{x_{1}-x_{a}}{x_{b}-x_{a}}$

and the fractional interval $f_{2}$ for $P_{2}$ is defined by

$f_{2}=\frac{x_{2}-x_{c}}{x_{d}-x_{c}}$.

If the distributions of the two combined components are fully correlated then only the combination of $P_{1}\left(f_{1}\right)$ and $P_{2}\left(f_{2}=f_{1}\right)$ contribute to the combined distribution. When $P_{1}$ and $P_{2}$ are assumed to be independent all combinations of $f_{1}$ and $f_{2}$ yield contributions to the combined distribution.

Therefore the fractional difference $f_{d}$ is defined as

$f_{d}=\left|f_{1}\left(x_{1}\right)-f_{2}\left(x_{2}\right)\right|$,

which indicates how far the fractional intervals of $x_{1}$ and $x_{2}$ are separated: e.g., if $f_{d}=0$ then $x_{1}$ and $x_{2}$ are at the same fractional interval. For the anticorrelation case when $r$ is negative, $f_{d}$ has to be

$f_{d}=\left|f_{1}\left(x_{1}\right)-\left(1-f_{2}\left(x_{2}\right)\right)\right|$.

Subsequently a correlation function $\Psi\left(x_{1}, x_{2}\right)$ is constructed which is a function of $f_{d}$ at the $0-1$ interval. This function is parameterized by the correlation $r$ : high $r$ values generate contributions to the combined distributions if $x_{1}$ and $x_{2}$ are close to each other, while $r=0$ indicates that the distributions are independent. A function which satisfies this criteria and which is used in the analysis is

$\Psi\left(x_{1}, x_{2}\right)=e^{-\left(\frac{0.6 f_{d}\left(x_{1}, x_{2}\right)}{1-|r|}\right)^{12}}$, where the numbers 0.6 and 12 control the correct behavior of $\Psi$, but their precise values are slightly arbitrary. Examples of three different $r$ values are shown in Fig. A5. Over the interval $r=0-1 \mathrm{Eq}$. (A5) is defined as

$\Psi\left(x_{1}, x_{2}\right)= \begin{cases}1 & \begin{array}{l}\text { independent } \\ \text { distributions }\end{array} \\ e^{-\left(\frac{0.6 f_{d}\left(x_{1}, x_{2}\right)}{I-|r|}\right)^{12}} & \begin{array}{l}\text { for } a \leq x_{1} \leq b \\ \text { and } c \leq x_{2} \leq d \\ \text { else }\end{array} \\ 0 & \end{cases}$

Note that in Eq. (A4) we use the absolute value, this reduces the $f_{d}$ interval from -1 to 1 to 0 to 1 and enables the possibility to use an odd power in the exponent of the $\Psi$ function in Eq. (A5).

The generalized form of Eq. (1) for combining two correlated SLC probability distributions $P_{1}$ and $P_{2}$ becomes

$$
\begin{gathered}
P(x)=\sum_{m=c}^{d} P_{1}(x-m \Delta x) P_{2}(m \Delta x) \\
\Psi(x-m \Delta x, m \Delta x),
\end{gathered}
$$

which reduces to Eq. (1) in case that $P_{1}$ and $P_{2}$ are independent.

The numerical form of Eq. (A7) adopted in the study is

$P\left(i-i_{0}\right)=\sum_{m=c}^{d} P_{1}(i-m) P_{2}(m) \Psi(i-m, m)$,

where $i_{0}$ is the counter along the $x$ axis at $x=0$, so $c$ and $d$ could be taken relative to $i_{0}$. Note that the correlation function $\Psi$ depends on the interval boundaries $x_{a}, x_{b}, x_{c}$ and $x_{d}$ as well. Other correlation functions which satisfy the global behavior in Fig. A5 for such $r$ values may be used, but they do not yield qualitatively different results for combining correlated probability distributions. 


\section{A2 Additional figures}
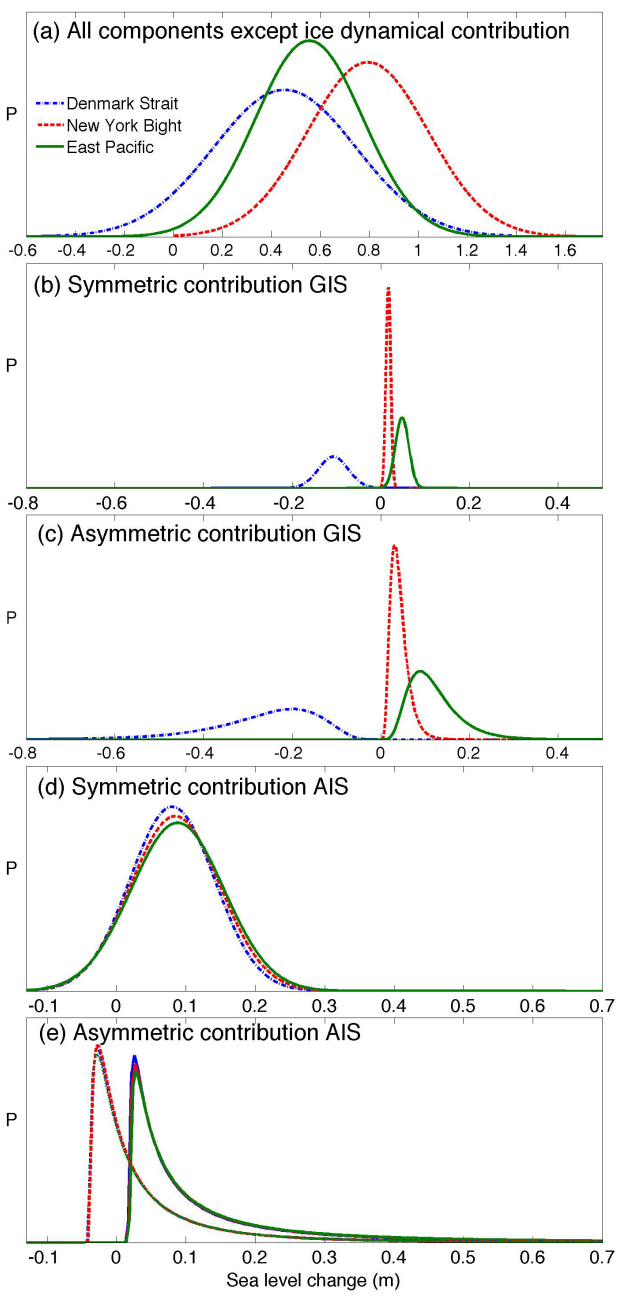

Figure A1. Contributions of dynamical ice sheets mass loss to sea level change at three locations (depicted in Fig. 4a). (a) All regional changes in sea level change (SLC), except the dynamical ice sheet mass loss of Greenland and Antarctica, following RCP8.5 (Slangen et al., 2014). The dynamical ice sheet contribution to SLC of the Greenland ice sheet based on (b) the symmetric IPCC-AR5 probability distribution (Church et al., 2013) and (c) the VW15 asymmetric probability distribution (De Vries and Van de Wal, 2015). The dynamical ice sheet contribution to SLC of the Antarctic ice sheet based on (d) the symmetric IPCC-AR5 probability distribution (Church et al., 2013) and (e) the VW15 asymmetric probability distribution (De Vries and Van de Wal, 2015) with a distinction for East Antarctica only and West Antarctica only. Note the large tail to the left side with negative SLC values for the GIS contribution (b, c) for the Denmark Strait located close to the GIS and the large tail towards positive SLC values (e) for the asymmetric EAIS and WAIS contributions. (a)

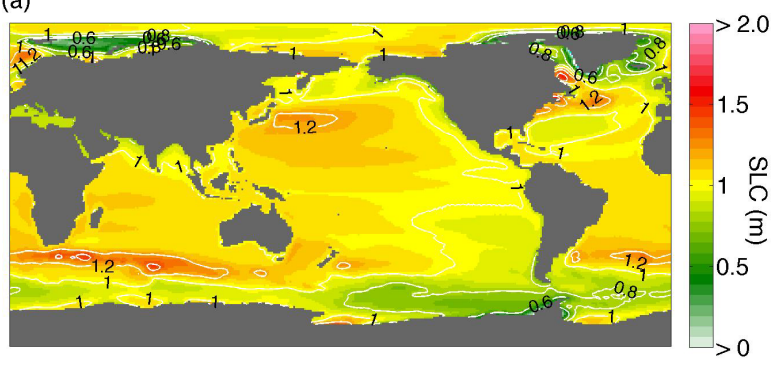

(b)

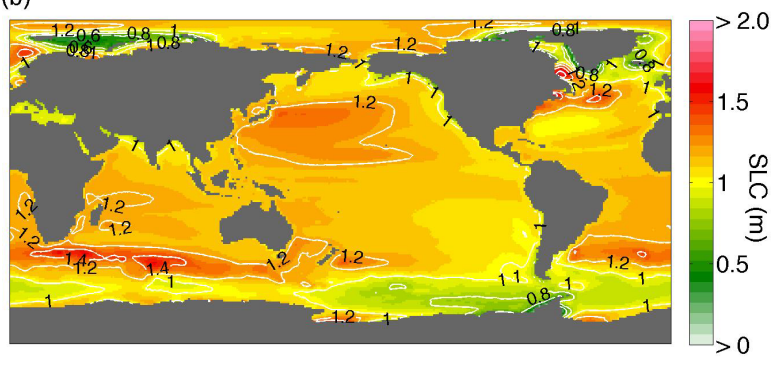

(c)

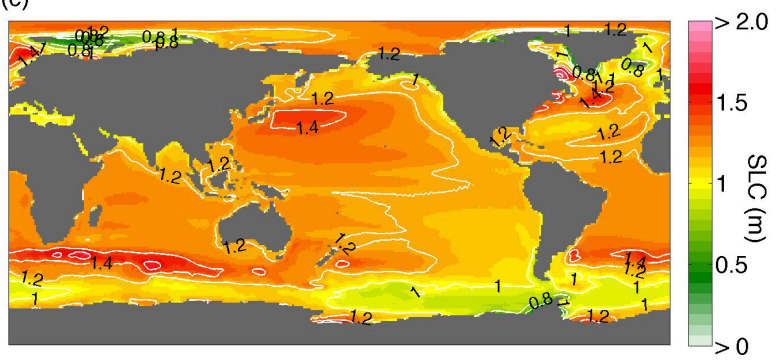

Figure A2. Sea level change (SLC) projections for high-end percentiles by 2090 with symmetric IPCC-based distribution of dynamical ice sheet mass loss combined with the regional SLC projection of Slangen et al. (2014) following climate scenario RCP8.5, (a) 90th, (b) 95th and (c) 97.5 th percentiles. 
(a)

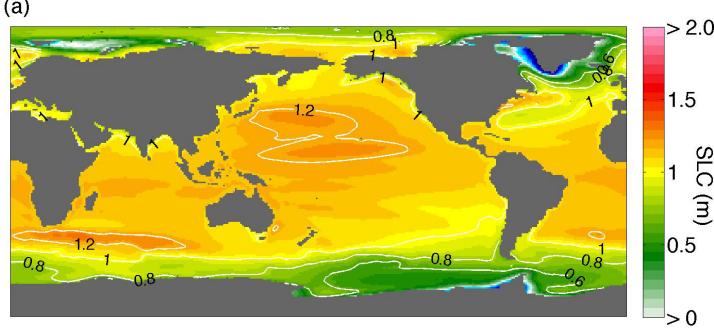

(b)

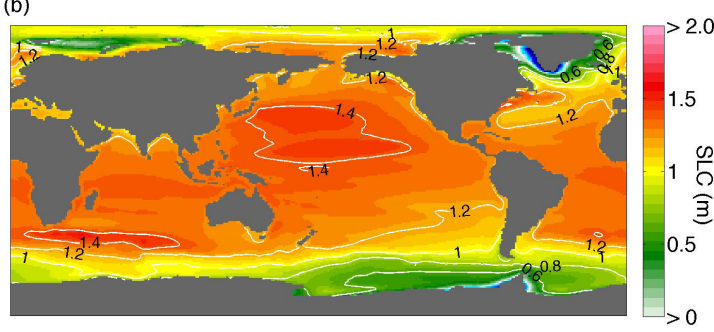

(c)

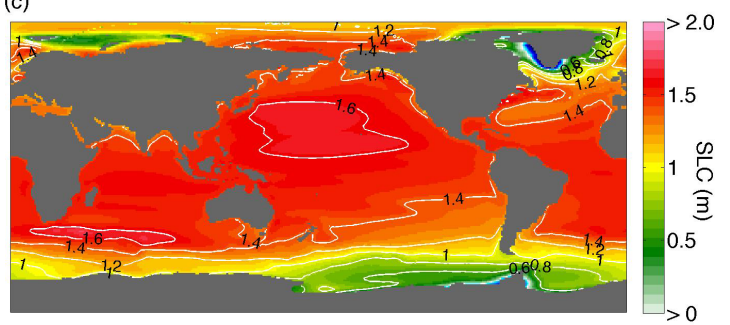

(d)

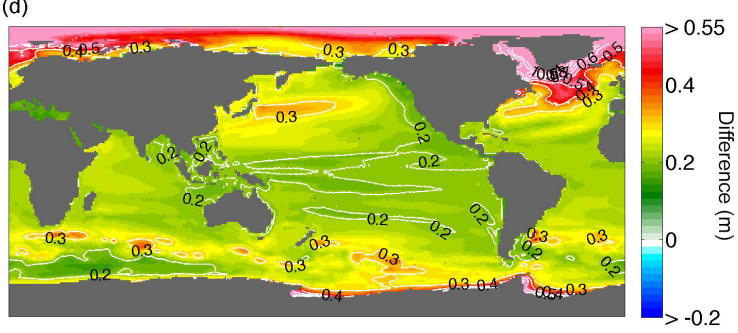

(e)

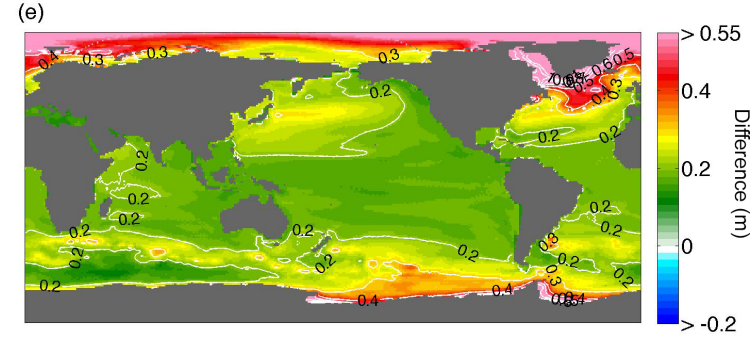

(f)

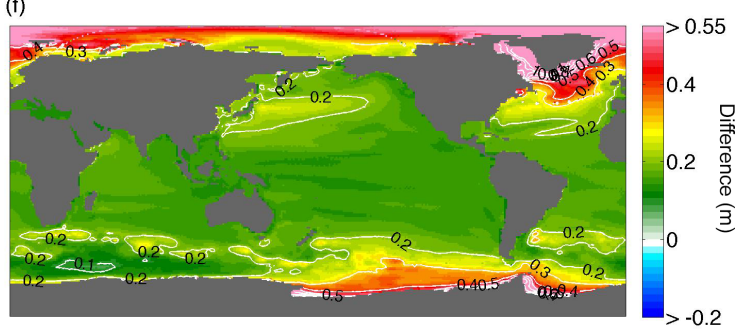

Figure A3. Sea level change (SLC) projections for high-end percentiles and the change therein by 2090 if asymmetric VW15 dynamical ice sheet mass loss is partly correlated with climate-change-induced SLC changes. Left column: (a) 90th, (b) 95th and (c) 97.5 th percentile for the asymmetric VW15 distribution of dynamical ice sheet mass loss combined with regional SLC projections following RCP8.5 (Slangen et al., 2014). It is assumed that the dynamical ice sheet mass loss of Greenland ice sheet is fully correlated with all other regional changes in SLC. Dynamical ice sheet mass loss of West Antarctic ice sheet is assumed to be $70 \%$ when correlated with this combined probability distribution. The dynamical ice mass loss contribution of East Antarctic ice sheet is assumed to be fully uncorrelated with the other components. Right column: difference between the uncorrelated and partly correlated simulations (both combined with regional SLC projections following RCP8.5 (Slangen et al., 2014) and VW15 distributions) for the (d) 90th, (e) 95th and (f) 97.5th percentile. 
(a)

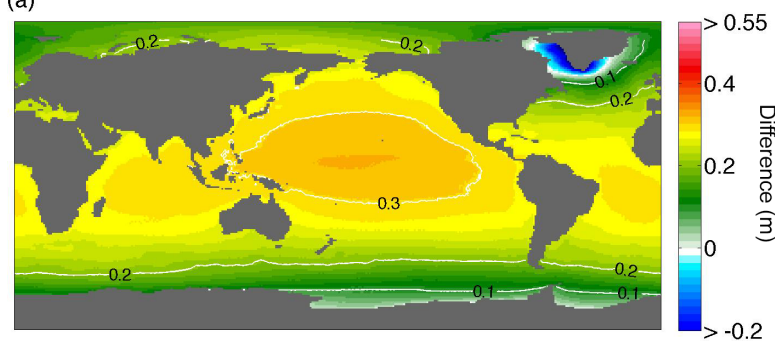

(b)

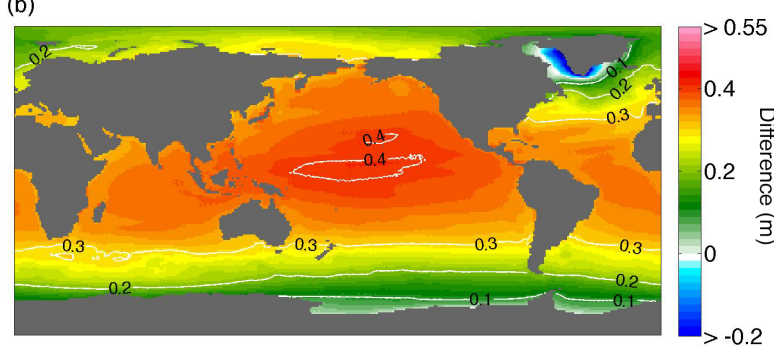

(c)

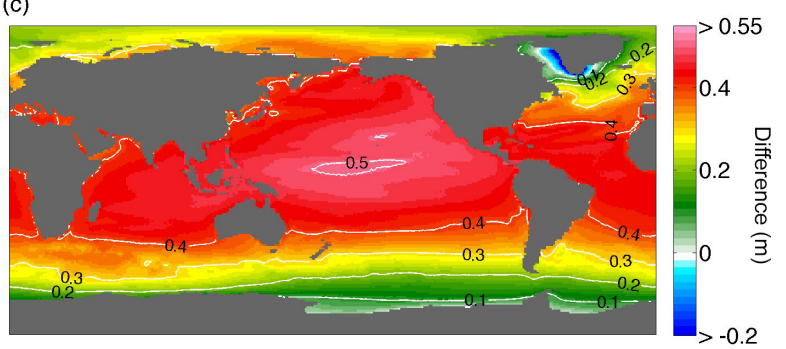

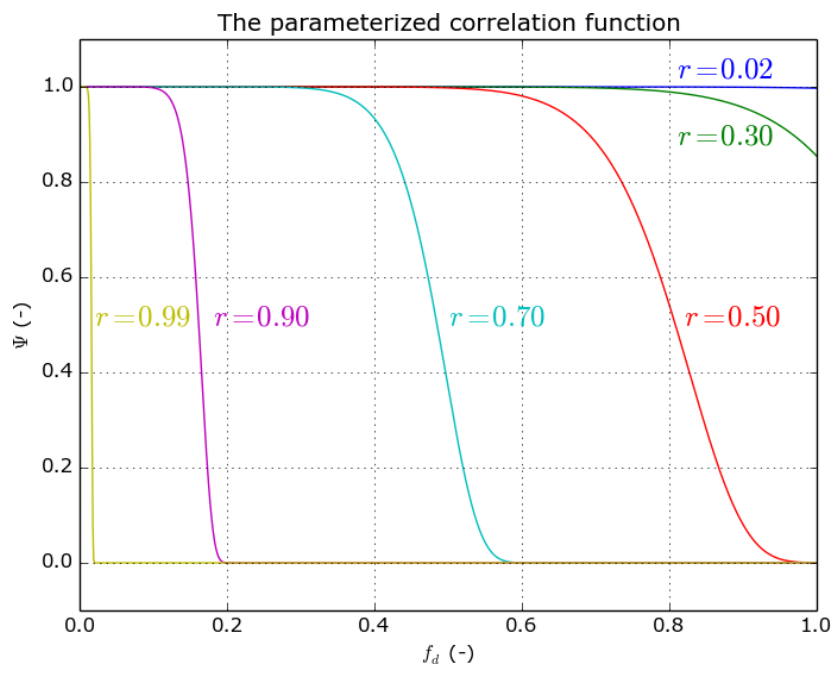

Figure A5. $\Psi\left(f_{d}\left(x_{1}, x_{2}\right)\right)$ as in Eq. (A7) for various $r$. The correlation $r$ is a parameter in $\Psi$ which varies from 0 to 1 . Here $\Psi$ is shown as function of $f_{d}$ for several $r$ values, as indicated by the labels in the figure.
Figure A4. Difference between the (a) 90th, (b) 95th and (c) 97.5th percentile for the asymmetric VW15 simulations (dynamical ice sheet mass loss of the Greenland, East and West Antarctic ice sheet (GIS, EAIS and WAIS) according to De Vries and Van de Wal, 2015) and the asymmetric Ritz simulations (dynamical ice sheet mass loss of EAIS and WAIS according to Ritz et al. (2015), GIS following the symmetric IPCC-AR5 distribution), both combined with regional SLC projections of Slangen et al. (2014) following climate scenario RCP8.5. 
Author contributions. RSWvdW conceived the study and designed the method with TJR. TJR developed the SEAWISE software. RCdW carried out the analysis and wrote the manuscript under guidance of RSWvdW. RCdW and TJR wrote the Methods section. ABAS, HdV and TE prepared the data for the different contributions to SLC. All authors contributed to editing the manuscript.

Competing interests. The authors declare that they have no conflict of interest.

Acknowledgements. Renske C. de Winter and Aimée B. A. Slangen acknowledge the ALW-NPP program of NWO. Thomas J. Reerink is funded by Netherlands Earth System Science Center.

Edited by: Paolo Tarolli

Reviewed by: two anonymous referees

\section{References}

Bamber, J. L. and Aspinall, W. P.: An expert judgement assessment of future sea level rise from the ice sheets, Nature Climate Change, 3, 424-427, 2013.

Cazenave, A. and Le Cozannet, G.: Sea level rise and its coastal impacts, Earth's Future, 2, 15-34, https://doi.org/10.1002/2013EF000188, 2014.

Church, J. A., Clark, P. U., Cazenave, A., Gregory, J., Jevrejeva, S., Levermann, A., Merrifield, M. A., Milne, G. A., Nerem, R. S., Nunn, P. D., Payne, A. J., Pfeffer, W. T., Stammer, D., and Unnikrishnan, A.: Sea Level Change, in: Climate Change 2013: The Physical Science Basis. Contribution of Working Group I to the Fifth Assessment Report of the Intergovernmental Panel on Climate Change, Cambridge University Press, Cambridge, UK and New York, NY, USA, 2013.

Clark, P. U., Church, J. A., Gregory, J. M., and Payne, A. J.: Recent Progress in Understanding and Projecting Regional and Global Mean Sea Level Change, Current Climate Change Reports, 1, 224-246, https://doi.org/10.1007/s40641-015-0024-4, 2015.

De Vries, H. and Van de Wal, R. S. W.: How to interpret expert judgment assessments of 21 st century sea-level rise, Climatic Change, 130, 87-100, https://doi.org/10.1007/s10584-015-1346$\mathrm{x}, 2015$.

De Vries, H., Katsman, C., and Drijfhout, S.: Constructing scenarios of regional sea level change using global temperature pathways, Environ. Res. Lett., 9, 115007, https://doi.org/10.1088/1748-9326/9/11/115007, 2014.

De Winter, R. and Reerink, T.: SEAWISE data, Impact of asymmetric uncertainties in ice sheet dynamics on regional sea level projections, available at: https://dataverse.nl/dataset.xhtml? persistentId=hdl:10411/X8BTEB (last access: 28 November 2017), DataverseNL Dataverse, V1, 2017.

De Winter, R. C. and Ruessink, B. G.: Sensitivity analysis of climate change impacts on dune erosion: case study for the Dutch Holland coast, Climatic Change, 141, 685-701, https://doi.org/10.1007/s10584-017-1922-3, 2017.

DeConto, R. M. and Pollard, D.: Contribution of Antarctica to past and future sea-level rise, Nature, 531, 591-597, 2016.
Favier, L., Durand, G., Cornford, S. L., Gudmundsson, G. H., Gagliardini, O., Gillet-Chaulet, F., Zwinger, T., Payne, A. J., and Le Brocq, A. M.: Retreat of Pine Island Glacier controlled by marine ice-sheet instability, Nature Climate Change, 4, 117-121, 2014.

Golledge, N., Kowalewski, D., Naish, T., Levy, R., Fogwill, C., and Gasson, E.: The multi-millennial Antarctic commitment to future sea-level rise, Nature, 526, 421-425, 2015.

Gregory, J. M., Church, J. A., Clark, P. U., Payne, A. J., Merrifield, M. A., Nerem, R. S., Nunn, P. D., Pfeffer, W. T., and Stammer, D.: Comment on "Expert assessment of sea-level rise by AD 2100 and AD 2300", by Horton et al. (2014), Quaternary Sci. Rev., 97, 193-194, 2014.

Grinsted, A., Jevrejeva, S., Riva, R. E. M., and Dahl-Jensen, D.: Sea level rise projections for Northern Europe under RCP8.5, Clim. Res., 64, 15-23, 2015.

Hinkel, J., Jaeger, C., Nicholls, R. J., Lowe, J., Renn, O., and Peijun, S.: Sea-level rise scenarios and coastal risk management, Nature Climate Change, 5, 188-190, 2015.

Horton, B. P., Rahmstorf, S., Engelhart, S. E., and Kemp, A. C.: Expert assessment of sea-level rise by AD 2100 and AD 2300, Quaternary Sci. Rev., 84, 1-6, 2014.

Jacobs, S. S., Jenkins, A., Giulivi, C. F., and Dutrieux, P.: Stronger ocean circulation and increased melting under Pine Island Glacier ice shelf, Nat. Geosci., 4, 519-523, 2011.

Jonkman, S., Jongejan, R., and Maaskant, B.: The Use of Individual and Societal Risk Criteria Within the Dutch Flood Safety PolicyNationwide Estimates of Societal Risk and Policy Applications, Risk Anal., 31, 282-300, 2011.

Katsman, C. A., Sterl, A., Beersma, J. J., van den Brink, H. W., Church, J. A., Hazeleger, W., Kopp, R. E., Kroon, D., Kwadijk, J., Lammersen, R., Lowe, J., Oppenheimer, M., Plag, H. P., Ridley, J., von Storch, H., Vaughan, D. G., Vellinga, P., Vermeersen, L. L. A., van de Wal, R. S. W., and Weisse, R.: Exploring highend scenarios for local sea level rise to develop flood protection strategies for a low-lying delta-the Netherlands as an example, Climatic Change, 109, 617-645, https://doi.org/10.1007/s10584011-0037-5, 2011.

Kopp, R. E., Horton, R. M., Little, C. M., Mitrovica, J. X., Oppenheimer, M., Rasmussen, D. J., Strauss, B. H., and Tebaldi, C.: Probabilistic 21st and 22nd century sea-level projections at a global network of tide-gauge sites, Earth's Future, 2, 383-406, https://doi.org/10.1002/2014EF000239, 2014.

Le Bars, D., Drijfhout, S., and De Vries, H.: A high-end sea level rise probabilistic projection including rapid Antarctic ice sheet mass loss, Environ. Res. Lett., 12, 044013, https://doi.org/10.1088/1748-9326/aa6512, 2017.

Little, C., Oppenheimer, M., and Urban, N.: Upper bounds on twenty-first-century Antarctic ice loss assessed using a probabilistic framework, Nature Climate Change, 3, 654-659, 2013.

Lyu, K., Zhang, X., Church, J. A., Slangen, A. B. A., and Hu, J.: Time of emergence for regional sea-level change, Nature Climate Change, 4, 1006-1010, 2014.

Mitrovica, J. X., Tamisiea, M. E., Davis, J. L., and Milne, G. A.: Recent mass balance of polar ice sheets inferred from patterns of global sea-level change, Nature, 409, 1026-1029, 2001.

Moss, R., Edmonds, J., Hibbard, K., Manning, M., Rose, S., Van Vuuren, D., T. R. C., Emori, S., Kainuma, M., Kram, T., Meehl, G., Mitchell, J., Nakicenovic, N., Ri- 
ahi, K., Smith, S., Stouffer, R., Thomson, A., Weyant, J., and Wilbanks, T.: The next generation of scenarios for climate change research and assessment, Nature, 463, 747-756, https://doi.org/10.1038/nature08823, 2010.

Nicholls, R. J., Marinova, N., Lowe, J. A., Brown, S., Vellinga, P., De Gusmão, D., Hinkel, J., and Tol, R. S. J.: Sea-level rise and its possible impacts given a "beyond $4{ }^{\circ} \mathrm{C}$ world" in the twenty-first century, Philos. T. R. Soc. A, 369, 161-181, 2011.

Nick, F., Vieli, A., Andersen, M., Joughin, I., Payne, A., Edwards, T., Pattyn, F., and Van De Wal, R.: Future sea-level rise from Greenland's main outlet glaciers in a warming climate, Nature, 497, 235-238, 2013.

Pattyn, F., Schoof, C., Perichon, L., Hindmarsh, R. C. A., Bueler, E., de Fleurian, B., Durand, G., Gagliardini, O., Gladstone, R., Goldberg, D., Gudmundsson, G. H., Huybrechts, P., Lee, V., Nick, F. M., Payne, A. J., Pollard, D., Rybak, O., Saito, F., and Vieli, A.: Results of the Marine Ice Sheet Model Intercomparison Project, MISMIP, The Cryosphere, 6, 573-588, https://doi.org/10.5194/tc-6-573-2012, 2012.

Perrette, M., Landerer, F., Riva, R., Frieler, K., and Meinshausen, M.: A scaling approach to project regional sea level rise and its uncertainties, Earth Syst. Dynam., 4, 11-29, https://doi.org/10.5194/esd-4-11-2013, 2013.

Pollard, D., DeConto, R. M., and Alley, R. B.: Potential Antarctic Ice Sheet retreat driven by hydrofracturing and ice cliff failure, Earth Planet. Sc. Lett., 412, 112-121, 2015.

Ritz, C., Edwards, T., Durand, G., Payne, A., Peyaud, V., and Hindmarsh, R.: Potential sea-level rise from Antarctic ice-sheet instability constrained by observations, Nature, 528, 115-118, 2015.

Sallenger Jr., A. H., Doran, K. S., and Howd, P. A.: Hotspot of accelerated sea-level rise on the Atlantic coast of North America, Nature Climate Change, 2, 884-888, https://doi.org/10.1038/nclimate1597, 2012.
Santamaría-Gómez, A., Gravelle, M., and Wöppelmann, G.: Longterm vertical land motion from double-differenced tide gauge and satellite altimetry data, J. Geodesy, 88, 207-222, 2014.

Slangen, A. B. A., Katsman, C. A., van de Wal, R. S. W., Vermeersen, L. L. A., and Riva, R. E. M.: Towards regional projections of twenty-first century sea-level change based on IPCC SRES scenarios, Clim. Dynam., 38, 1191-1209, 2012.

Slangen, A. B. A., van de Wal, R. S. W., Reerink, T. J., de Winter, R. C., Hunter, J. R., Woodworth, P. L., and Edwards, T.: The Impact of Uncertainties in Ice Sheet Dynamics on Sea-Level Allowances at Tide Gauge Locations, Journal of Marine Science and Engineering, 5, 21, https://doi.org/10.3390/jmse5020021, 2017.

Slangen, A. B. A., Carson, M., Katsman, C. A., van de Wal, R. S. W., Koehl, A., Vermeersen, L. L. A., and Stammer, D.: Projecting twenty-first century regional sea-level changes, Climatic Change, 124, 317-332, https://doi.org/10.1007/s10584014-1080-9, 2014.

Sriver, R., Urban, N., Olson, R., and Keller, K.: Toward a physically plausible upper bound of sea-level rise projections, Climatic Change, 115, 893-902, 2012.

Vieli, A. and Payne, A. J.: Assessing the ability of numerical ice sheet models to simulate grounding line migration, J. Geophys. Res.-Earth, 10, F01003, https://doi.org/10.1029/2004JF000202, 2005.

Yin, J. and Goddard, P.: Oceanic control of sea level rise patterns along the East Coast of the United States, Geophys. Res. Lett., 40, 5514-5520, 2013. 